\title{
A novel target enrichment strategy in next-generation sequencing through 7-deaza-dGTP-resistant enzymatic digestion
}

\author{
Peng Peng ${ }^{1,3}$, Yanjuan Xu' ${ }^{1}$ Adrian M. Di Bisceglie ${ }^{1,2}$ and Xiaofeng Fan ${ }^{1,2^{*}}$ (1)
}

\begin{abstract}
Objective: Owing to the overwhelming dominance of human and commensal microbe sequences, low efficiency is a major concern in clinical viral sequencing using next-generation sequencing. DNA composed of 7-deaza-2'deoxyguanosine $5^{\prime}$-triphosphate ( $\mathrm{c}^{7} \mathrm{dGTP}$ ), an analog of deoxyguanosine triphosphate (dGTP), is resistant to selective restriction enzymes. This characteristic has been utilized to develop a novel strategy for target enrichment in nextgeneration sequencing.

Results: The new enrichment strategy is named target enrichment via enzymatic digestion in next-generation sequencing (TEEDseq). It combined 7-deaza-2'-deoxyguanosine 5'-triphosphate ( $c^{7} d G T P$ )-involved primer extension, splinter-assisted intracellular cyclization, $\left.c^{7} d G T P\right)$-resistant enzymatic digestion, and two-phase rolling cycle amplification. We first estimated c7dGTP for its efficiency in PCR amplification and its resistance to three restriction enzymes, Alul, Haelll, and HpyCH4V. We then evaluated TEEDseq using a serum sample spiked with a 1311-bp hepatitis B virus (HBV) fragment. TEEDseq achieved an HBV on-target rate of $3.31 \pm 0.39 \%$, which was equivalent to $454 \times$ the enrichment of direct Illumina sequencing. Therefore, the current study has provided a concept proof for TEEDseq as an alternative option for clinical viral sequencing that requires an enrichment in next-generation sequencing.
\end{abstract}

Keywords: Next-generation sequencing, Target enrichment, 7-deaza-2'-deoxyguanosine 5'-triphosphate, Hepatitis B virus

\section{Introduction}

In current clinical viral genome sequencing, next-generation sequencing (NGS) is a frequent choice that provides an unbiased high resolution of mutation profile in a genome-wide manner [1]. Because of an overwhelming dominance of human genetic content in clinical specimens, a major limitation of this approach is its low

\footnotetext{
*Correspondence: xiaofeng.fan@health.slu.edu

${ }^{1}$ Division of Gastroenterology \& Hepatology, Department of Internal Medicine, Saint Louis University School of Medicine, St. Louis, MO 63104, USA

Full list of author information is available at the end of the article
}

efficiency, which is rarely higher than $1 \%$ of viral sequencing reads in NGS output [1]. Among numerous virusenriched methods, capture sequencing, employing a hybridization step after NGS library construction, comes out as the most efficient strategy to enrich viral sequences [1]. However, this strategy is associated with a dramatic cost increase as it requires the synthesis of expensive biotin labeled virus-specific probes (baits) and streptavidin beads [2]. The inclusion of such a hybridization step after initial library preparation also makes the entire NGS pipeline a lengthy procedure. Most human viruses, such as hepatitis B virus (HBV), hepatitis $\mathrm{C}$ virus (HCV), HIV, and coronavirus, have a genome less than $30 \mathrm{~kb}$ in size.

(c) The Author(s) 2020. This article is licensed under a Creative Commons Attribution 4.0 International License, which permits use, sharing, adaptation, distribution and reproduction in any medium or format, as long as you give appropriate credit to the original author(s) and the source, provide a link to the Creative Commons licence, and indicate if changes were made. The images or other third party material in this article are included in the article's Creative Commons licence, unless indicated otherwise in a credit line to the material. If material is not included in the article's Creative Commons licence and your intended use is not permitted by statutory regulation or exceeds the permitted use, you will need to obtain permission directly from the copyright holder. To view a copy of this licence, visit http://creativeco mmons.org/licenses/by/4.0/. The Creative Commons Public Domain Dedication waiver (http://creativecommons.org/publicdomain/ zero/1.0/) applies to the data made available in this article, unless otherwise stated in a credit line to the data. 
If the viral on-target rate consistently exceeds $1 \%$, current NGS approach is actually powerful enough to satisfy clinical and research needs. For instance, a $1 \% \mathrm{HCV}$ ontarget rate in 5 million of $2 \times 150$ bp paired ended reads give a depth at $1562 \times$, which already crosses a saturation point $(1100 \times)$ for $\mathrm{HCV}$ viral population dissection with a mutation frequency resolved at $1 \%$ [3]. To achieve this goal, we provide an alternative option for viral sequence enrichment that does not require a probe-based hybridization step. Our method, named NGS with target enrichment via enzymatic digestion (TEEDseq), is dependent on 7-deaza-2'-deoxyguanosine $5^{\prime}$-triphosphate ( $\mathrm{c}^{7} \mathrm{dGTP}$ ), an analog of deoxyguanosine triphosphate (dGTP). Due to its ability to relax DNA secondary structure, $c^{7} d G T P$ is widely used in PCR and Sanger sequencing $[4,5]$. DNA molecules composed of $c^{7} d G T P$ show steric alteration that is resistant to some restriction enzymes with the recognition motifs containing guanosine [6]. This unique characteristic of $\mathrm{c}^{7} \mathrm{dGTP}$ is used to accomplish the enrichment of a sequencing target.

\section{Main text}

\section{Materials and methods}

PCR amplification efficiency using $\mathrm{c}^{7} \mathrm{dGTP}$ was first estimated using an HBV plasmid as the template [7]. A 30 -cycle PCR was done in a $50 \mu \mathrm{L}$ reaction containing $1 \times$ Q5 DNA polymerase buffer, $0.8 \mathrm{mM}$ dNTPs, each $0.4 \mu \mathrm{M}$ of primers HBVF1 and HBVR1 (Table 1), and 1 unit of Q5 DNA polymerase [New England Biolabs (NEB), Ipswich, MA]. In the parallel reaction, dGTPs was completely replaced by $c^{7}$ dGTP (Roche Molecular Systems, Madison, WI). After the purification with QIAquick PCR Purification Kit (Qiagen, Valencia, CA), the PCR product was quantitated in NanoDrop 2000 Spectrophotometer (Thermo Fisher Scientific, Waltham, MA).

Next, we tested the resistance of $c^{7} d G T P$ to restriction enzymes. The above PCR was repeated with primer HBVR $1^{\mathrm{p}}$ containing a phosphate at $5^{\prime}$ end. PCR product was purified and digested by Lambda exonuclease (NEB) that favored the digestion of $5^{\prime}$ phosphate strand [8]. Consequently, both single-strand DNA (ssDNA) and doublestrand DNA (dsDNA) were generated and used for the digestion of three restriction enzymes (AluI, HaeIII, and HpyCH4V) (NEB) that were carefully selected based on their recognition motifs and buffer compatibility. The experiment was repeated with PCR amplicon generated using $c^{7} d G T P$. Since $c^{7} d G T P$ was difficult to stain using ethidium bromide [9], PCR with a high cycle number $(\mathrm{n}=35)$ was conducted using an aliquot of $2 \mu \mathrm{L}$ enzyme reaction with primers HBVF2 and HBVR2 (Table 1).

Finally, TEEDseq was evaluated using a healthy donor serum sample spiked with a 1311-bp HBV PCR fragment at a concentration of $1 \times 10^{6}$ copies $/ \mathrm{mL}$, mimicking a concentration from viruses like HCV and HBV (Table 1) [10]. Total DNA was extracted from $0.5 \mathrm{~mL}$ of serum by QIAamp MinElute ccfDNA Kit (Qiagen, Valencia, CA) and eluted into $20 \mu \mathrm{L}$ Tris buffer. Entire $20 \mu \mathrm{L}$ extracted DNA was used for 5-cycle primer extension under 1 unit of Q5 DNA polymerase, $0.4 \mu \mathrm{M}$ primer HBVR4 (Table 1), and $0.8 \mathrm{mM}$ of dNTPs in which dGTP was completely replaced by $c^{7} d G T P$. The reaction was purified using MinElute PCR Purification Kit (Qiagen) and eluted into $20 \mu \mathrm{L}$ Tris buffer, followed by ligation in $30 \mu \mathrm{L}$ reaction consisting of $10 \mathrm{U}$ T4 DNA ligase and $0.5 \mu \mathrm{M}$ of the splinter at $14{ }^{\circ} \mathrm{C}$ overnight. After heat inactivation, the enzyme complex (AluI 10 U, HeaIII 10 U, HpyCH4V 5U, Exonuclease I $50 \mathrm{U}$, and Exonuclease III $20 \mathrm{U}$ ) was added

Table 1 List of the oligonucleotides used in the study

\begin{tabular}{|c|c|c|c|c|}
\hline Oligonucleotide & Polarity & Sequence $\left(5^{\prime} \rightarrow 3^{\prime}\right)$ & Position & Product size/note \\
\hline HBVF1 & Sense & actctctcgtccecttctcc & $1479-1498$ & 504 bp \\
\hline HBVR1 & Antisense & tgacggaaggaaagaagtcag & $1962-1982$ & \\
\hline $\mathrm{HBVR}^{\mathrm{p}}$ & Antisense & Ptgacggaaggaaagaagtcag & 1962-1982 & \\
\hline HBVF2 & Sense & ccttctccgtctgccgttc & $1491-1509$ & 488 bp \\
\hline HBVR2 & Antisense & ggaaggaaagaagtcagaaggc & 1957-1978 & \\
\hline HBVF3 & Sense & aacaggctttcactttctcgc & $1082-1102$ & 1311 bp \\
\hline HBVR3 & Antisense & cgagggagttcttcttctaggg & $2371-2392$ & \\
\hline HBVR4 & Antisense & ptccacactccgaaagagacc & $2257-2276$ & \\
\hline Splinter & NA & nnnnnnaggtgtgtSp3 & To facilitate intramolecular ligation & \\
\hline HBVR5 & Antisense & $\operatorname{tg} \operatorname{tg}^{*} g^{*} a$ & Target-specific RCA & \\
\hline C28 & NA & Sp18nnn*n*n & Non-specific RCA & \\
\hline
\end{tabular}

Position is according to the full-length HBV genome under GenBank accession number AB241115. Star donated phosphorothioate bonds to resist exonuclease activity of phi29 DNA polymerase. $\mathrm{P}$ in superscript indicated the modification of phosphate at the $5^{\prime}$ ends. C28 is the primer to eliminate primer-mediated artifacts from phi29 DNA polymerase-based multiple displacement amplification in our previous study [11]. Sp3, C3 spacer to block self-ligation of the splinter; Sp18, C18 spacer; NA, not applicable. All oligonucleotides were ordered from the Integrated DNA Technologies, Coralville, IA 
to bring the reaction up to $45 \mu \mathrm{L}$ volume in $1 \times$ CutSmart buffer. $3 \mathrm{~h}$ after the incubation at $37^{\circ} \mathrm{C}$, the reaction was heat-inactivated and used for RCA with $1 \mu \mathrm{M}$ target-specific primer HBVR5 (Table 1 ) at $30{ }^{\circ} \mathrm{C}$ for the first $12 \mathrm{~h}$ and then $4 \mathrm{~h}$ at $28^{\circ} \mathrm{C}$ with $80 \mu \mathrm{M}$ of $\mathrm{C} 28$ primer (Table 1 ). The final product was around $12 \mathrm{~kb}$ in size with an average yield of $1.8 \mu \mathrm{g}$ after purification using QIAprep Spin Miniprep Kit (Qiagen). The product was subjected to Illumina sequencing $(1 \times 250 \mathrm{nt}$ single-end read), followed by data analysis as we previously described [11, 12]. We tested four options: full TEEDseq protocol (a), TEEDseq with the omission of three restriction enzyme (b), direct sequencing using Illumina Nextera Flex for plasma/serum kit (c), and full TEEDseq using the same serum sample without the spike-in of the HBV fragment (d). Each option was set for three technical replicates.

\section{Results}

PCR using $c^{7}$ dGTP showed a weak band in ethidium bromide (EB)-stained gel (Additional file 1: Figure S1A), which was consistent with the previous report that $c^{7}$ dGTP was hardly stained using EB [9]. However, PCR quantification revealed a slightly lower yield with $\mathrm{c}^{7} \mathrm{dGTP}$ (Additional file 1: Figure S1B). This slight drop in PCR yield may also be attributed to the nature of $c^{7} d G T P$ rather than an authentic decrease. Hence, PCR with $c^{7} d G T P$ had similar efficiency to that using regular dGTP.

In the estimation of $c^{7} d G T P$ 's resistance to restriction enzymes, the amplicon had three AluI sites, one HaeIII site, and four HpyCH4V sites. While all three enzymes had a complete digestion of dsDNA, HpyCH4V cut both ssDNA and dsDNA (Additional file 1: Figure S1C). In comparison to dGTP, $\mathrm{c}^{7} \mathrm{dGTP}$ showed strong bands, suggesting a resistance to digestion. The combination of all three enzymes resulted in almost a complete digestion of both ssDNA and dsDNA, as indicated by a much weaker band (Additional file 1: Figure S1D). These experiments have demonstrated that dc7GTP is resistant to individual and combinatorial digestion of AluI, HaeIII, and HpyCH4V.

After read quality control [11, 12], one million of total reads had HBV-mapped reads at $33,153 \pm 3900$ $(3.31 \pm 0.39 \%), \quad 2638 \pm 750 \quad(0.26 \pm 0.07 \%), \quad 73 \pm 21$ $(0.007 \pm 0.0002 \%)$, and zero for options $\mathrm{a}, \mathrm{b}, \mathrm{c}$, and $\mathrm{d}$, respectively (Fig. 1). TEEDseq reached an enrichment $454 \times$ that of direct sequencing (option c). The recovery of HBV-mapped reads was 12.6 times higher in option a than in option b, illustrating the pivotal role of the three restriction enzymes. Using HiCUP [14], these enzymes together have 36,535,384 cuts (AluI 13,085,321; HaeIII 8,582,925; HpyCH4V 14,867,138) on the human genome
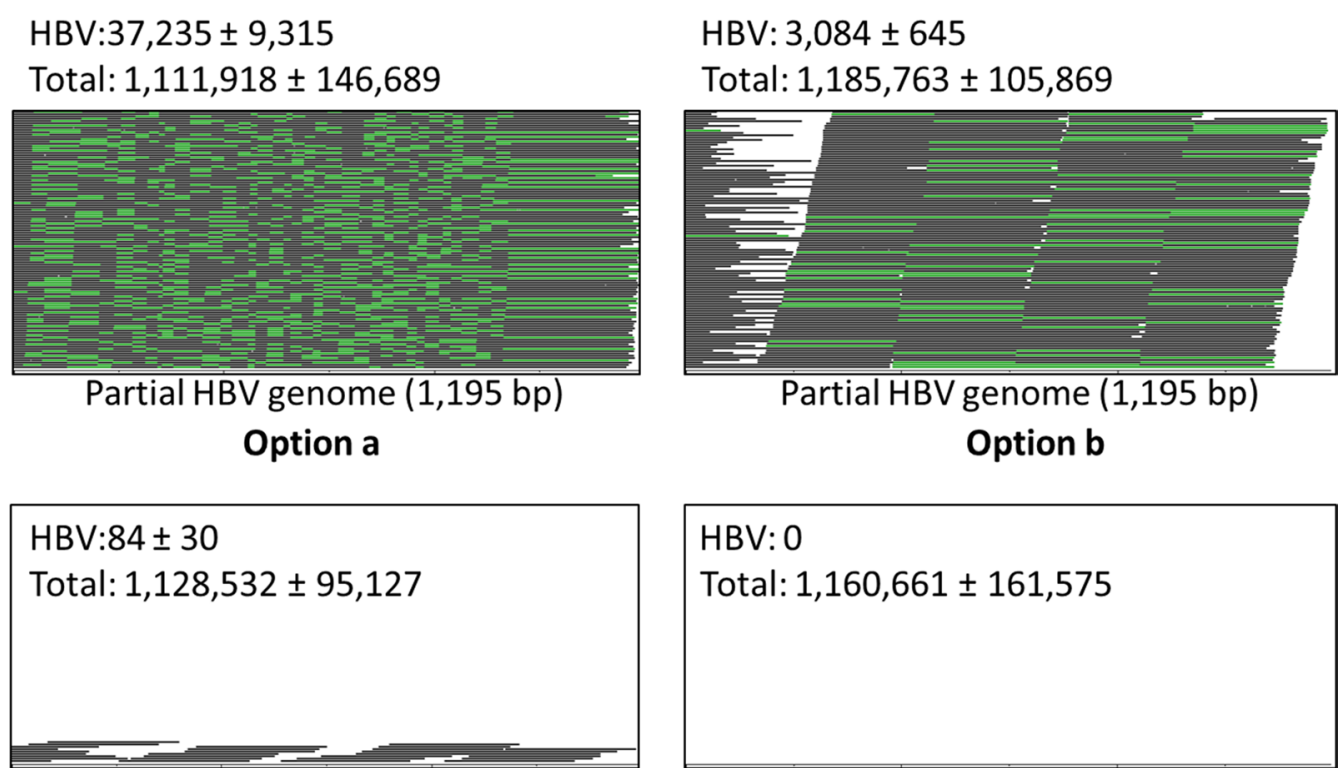

Partial HBV genome (1,195 bp)

Option c

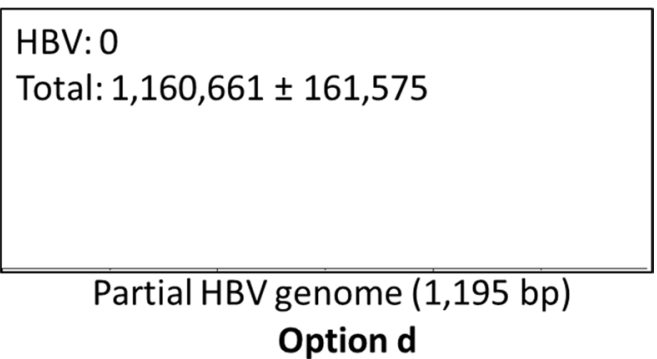

Fig. 1 HBV-specific read mapping among four options. Read-alignment on 1195-bp HBV genome sequence from the HBVR4 priming site was viewed in bam file using BamView [13]. Reads with matching start and end positions were collapsed into one line and are shown in green. Option a, b, and c used a serum sample spiked with 1311-bp HBV fragment. Option d had no HBV fragment spiked in the serum and served as a control. Each option was shown with the numbers (average and standard derivation) of HBV-mapped and total reads from three technical replicates after the quality control 
(building GRCh38). Their combination with exonucleases efficiently digested non-target background sequences.

\section{Discussion}

Our method consists of four steps: primer extension, splinter ligation, enzymatic digestion, and rolling circle amplification (RCA) (Fig. 2). Using a serum sample spiked with a partial HBV genome (1311 bp), TEEDseq achieved a $3.31 \%$ mapping rate. Under a probe-based hybridization strategy, genome-wide HBV capture sequencing does not necessarily have a high on-target rate, for instance, $<1 \%$ in a recent report [15]. Off-target effect may come from non-specific priming since there is significant microhomology between HBV and the human genome [16]. A more rigid primer design and conditions for primer extension could further enhance the enrichment.

In addition, TEEDseq has several technical features worthy of attention. Serum DNA is regarded as a lowbiomass sample. Its low DNA concentration, $435 \mathrm{ng} / \mathrm{mL}$ in the current study, naturally favors intracellular ligation that can be further facilitated using a splinter. Because intermolecular ligation is suppressed at a low DNA concentration, high concentration of templates, such as DNA extracted from tissue samples, need to be diluted prior to the ligation [17]. Second, we applied two-phase RCA amplification, target-specific and non-specific. The short incubation of non-specific RCA suppresses the amplification of contaminated sequences in the reagents, as observed in our recent studies $[18,19]$. Third, TEEDseq requires purification after primer extension. Afterwards, ligation, digestion, and RCA do not need purification because all enzymes have optimal activity in the CutSmart buffer (NEB). Therefore, these reactions can be conducted successively in the same tube. Finally, phi29 DNA polymerase used in RCA has a strong standdisplacement activity. This activity results in a hyperbranched structure of the final product that usually has a large size more than $10 \mathrm{~kb}$ [20]. Therefore, the final product can be directly used for fragmentation in NGS library preparation without the need of additional procedure, such as concatemerization. Taken together, our experiment, using a partial HBV genome (1311 bp) spiked in a serum sample, provides concept evidence that TEEDseq is a simple and cost-effective method for target enrichment in NGS. By using multiple primers to cover target genomes in primer extension, it can be applied to clinical viral sequencing as well as human genomic research.

\section{Limitations}

The current study is merely a proof of principle for TEEDseq. It remains to be improved toward a simple experimental method. For instance, time for the steps of ligation and RCA may be shortened. In addition, the efficiency and sensitivity of TEEDseq need to be further evaluated in clinical specimens.

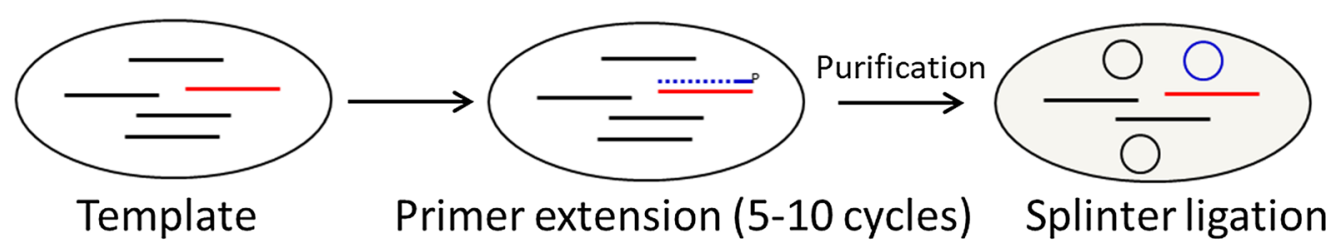

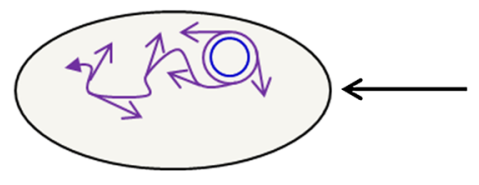

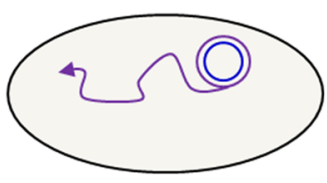

RCA (12 hours)

RCA (4 hours)

Non-specific

$\downarrow$ Purification

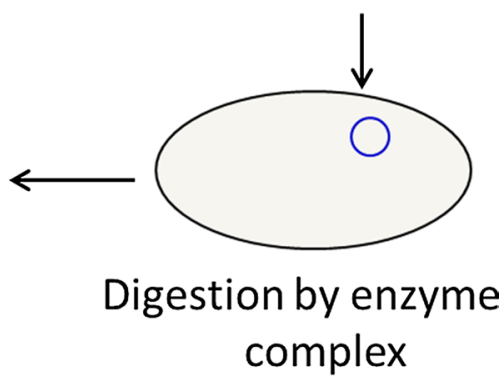

Library preparation $\longrightarrow$ Illumina sequencing

background - target

Fig. 2 The working flow of TEEDseq. Note that ligation, digestion, and RCA (grey-filled cycles) are placed in the same tube in a sequential manner. RCA, rolling cycling amplification 


\section{Supplementary information}

Supplementary information accompanies this paper at https://doi. org/10.1186/s13104-020-05292-y.

Additional file 1: Figure S1. Characteristics of C7dGTP-involved PCR amplification and digestion. PCR product with C7dGTP was hard to stain by EB (A) but having similar yield to dGTP (B). All three enzymes gave complete digestion of dsDNA generated from PCR using dGTP (C) but not C7dGTP, as examined via 35-cycle of PCR after digestion (D).

\section{Abbreviations}

TEEDseq: Target enrichment via enzymatic digestion in next generation sequencing; NGS: Next-generation sequencing; $c^{7} d G T P$ : 7-Deaza-2'deoxyguanosine 5'-triphosphate; dGTP: Deoxyguanosine triphosphate; RCA : Rolling cycling amplification; EB: Ethidium bromide; ssDNA: Single-strand DNA; dsDNA: Double-strand DNA; HBV: Hepatitis B virus; HCV: Hepatitis C virus.

\section{Acknowledgements}

We thank Dr. John Tavis (Saint Louis University) for providing a recombinant HBV plasmid that was used in the current study.

\section{Authors' contributions}

PP: Conception, experimental performance, data analysis, interpretation of data; YX: experimental performance; AMDB: Interpretation of data; XF: Conception, design of the work, data analysis, interpretation of data, writing manuscript. XF is the corresponding author. All authors read and approved the final manuscript.

\section{Funding}

This work was supported by the US National Institutes of Health (NIH) Grants Al139835 (X.F.)

\section{Availability of data and materials}

Sequence data in fasta format was deposited in the NCBI Sequence Read Archive (SRA) under BioProject ID: PRJNA626058. All other data generated or analyzed during this study are included in this published article [and its additional files].

\section{Ethics approval and consent to participate}

The serum sample used in the current study was provided by American Red Cross National Testing Lab in St. Louis. The serum sample was not collected for the current study. Instead, it was used in routine lab tests for transfusion safety and would be discarded if not used for research purpose. We obtained the serum sample that was not accompanied with any identity information. Hence, the consent was waived by the Saint Louis University Institutional Review Board that reviewed and approved the entire study protocol under the assurance no: FWA00005304

\section{Consent for publication}

Each author has agreed to publication of this manuscript.

\section{Competing interests}

The authors declare that they have no competing interests.

\section{Author details}

${ }^{1}$ Division of Gastroenterology \& Hepatology, Department of Internal Medicine, Saint Louis University School of Medicine, St. Louis, MO 63104, USA. ${ }^{2}$ Saint Louis University Liver Center, Saint Louis University School of Medicine, St. Louis, MO 63104, USA. ${ }^{3}$ Wuhan Pulmonary Hospital, Wuhan 430030, Hubei, China.

Received: 6 July 2020 Accepted: 12 September 2020

Published online: 18 September 2020

\section{References}

1. Houldcroft CJ, Beale MA, Breuer J. Clinical and biological insights from viral genome sequencing. Nat Rev Microbiol. 2017;15:183-92. https:// doi.org/10.1038/nrmicro.2016.182.
2. Briese T, Kapoor A, Mishra N, Jain K, Kumar A, Jabado OJ, et al. Virome capture sequencing enables sensitive viral diagnosis and comprehensive virome analysis. MBio. 2015;6:e01491. https://doi.org/10.1128/ mBio.01491-15.

3. Wang W, Zhang X, Xu Y, Weinstock GM, Di Bisceglie AM, Fan X. Highresolution quantification of hepatitis $C$ virus genome-wide mutation load and its correlation with the outcome of peginterferon-alpha2a and ribavirin combination therapy. PLoS ONE. 2014;9:e10013110. https ://doi.org/10.1371/journal.pone.0100131.

4. McConlogue L, Brow MA, Innis MA. Structure-independent DNA amplification by PCR using 7-deaza-2'-deoxyguanosine. Nucleic Acids Res. 1998;16:9869. https://doi.org/10.1093/nar/16.20.9869.

5. Motz M, Pääbo S, Kilger C. Improved cycle sequencing of GC-rich templates by a combination of nucleotide analogs. Biotechniques. 2000;29:268-70. https://doi.org/10.2144/00292st01.

6. Grime SK, Martin RL, Holaway BL. Inhibition of restriction enzyme cleavage of DNA modified with 7-deaza-dGTP. Nucleic Acids Res. 1991;19:2791. https://doi.org/10.1093/nar/19.10.2791.

7. Valenzuela P, Rall L, Zaldivar M, Quiroga M, Gray P, Rutter W. The nucleotide sequence of the hepatitis $B$ viral genome and the identification of the major viral genes. ICN-UCLA Symp Mol Cell Biol. 1980;18:57-70.

8. Civit L, Fragoso A, O'Sullivan CK. Evaluation of techniques for generation of single-stranded DNA for quantitative detection. Anal Biochem. 2012;431:132-8. https://doi.org/10.1016/j.ab.2012.09.003.

9. Weiss J, Zucht HD, Forssmann WG. Amplification of gene fragments with very high G/C content: C7dGTP and the problem of visualizing the amplification products. PCR Methods Appl. 1994:4:124-5. https://doi. org/10.1101/gr.4.2.124

10. Easterbrook PJ, Roberts T, Sands A, Peeling R. Diagnosis of viral hepatitis. Curr Opin HIV AIDS. 2017;12:302-14. https://doi.org/10.1097/ $\mathrm{COH} .0000000000000370$.

11. Wang W, Ren Y, Xu Y, Crosby S, Di Bisceglie AM, Fan X. Templatedependent multiple displacement amplification applied to profile human circulating RNA. Biotechniques. 2017;63:21-7. https://doi. org/10.2144/000114566.

12. Gorse GJ, Gira B, Patela GB, Fan X. Interpatient mutation spectrum of human coronavirus-OC43 revealed by illumina sequencing. J Med Virol. 2017:89:1330-8. https://doi.org/10.1002/jmv.24780.

13. Carver T, Harris SR, Otto TD, Berriman M, Parkhill J, McQuillan JA. BamView: visualizing and interpretation of next-generation sequencing read alignments. Brief Bioinform. 2013;14:203-12. https://doi. org/10.1093/bib/bbr073.

14. Wingett S, Ewels P, Furlan-Magaril M, Nagano T, Schoenfelder S, Fraser P et al. HiCUP: pipeline for mapping and processing Hi-C data. F1000Res. 2015:4:1310. https://doi.org/10.12688/f1000research.7334.1.

15. Zhao LH, Liu X, Yan HX, Li WY, Zeng X, Yang Y, et al. Genomic and oncogenic preference of HBV integration in hepatocellular carcinoma. Nat Commun. 2016;7:12992. https://doi.org/10.1038/ncomms12992.

16. Lin S. Analysis of the complexity of HBV-host junction sequences in patients with HBV-related hepatocellular carcinoma. Philadelphia: Ph.D. thesis. Drexel University College of Medicine; 2016.

17. Mason WS, Gill US, Litwin S, Zhou Y, Peri S, Pop O, et al. HBV DNA integration and clonal hepatocyte expansion in chronic hepatitis $B$ patients considered immune tolerant. Gastroenterology. 2016;151:98698. https://doi.org/10.1053/j.gastro.2016.07.012.

18. Li G, Zhou Z, Yao L, Xu Y, Wang L, Fan X. Full annotation of serum virome in Chinese blood donors with elevated alanine aminotransferase levels. Transfusion. 2019;59:3177-85. https://doi.org/10.1111/ trf.15476.

19. Ren $Y, X u Y$, Lee WM, Di Bisceglie AM, Fan X. In-depth serum virome analysis in acute liver failure patients with indeterminate etiology. Arch Virol. 2020;165:127-35. https://doi.org/10.1007/s00705-019-04466-9.

20. Binga EK, Lasken RS, Neufeld JD. Something from (almost) nothing: the impact of multiple displacement amplification on microbial ecology. ISME J. 2008;2:233-41. https://doi.org/10.1038/ismej.2008.10.

\section{Publisher's Note}

Springer Nature remains neutral with regard to jurisdictional claims in published maps and institutional affiliations. 